\title{
LatinOAmÉRICA y el Apocalipsis: ÍCONOS VISUALES en BLADE RUNNER y ELySIUM
}

\author{
Latin America and the Apocalypse: Visual Icons in Blade Runner and Elysium
}

Nelson Arteaga-Botello

Resumen: En el presente trabajo se subray a cómo las distopías fílmicas proyectan formas específicas de dominación y tensiones sociales que es posible encontrar en las sociedades contemporáneas. Se analizan las películas Blade Runner y Elysium a partir de cuatro elementos iconográficos que comparten: la ciudad de Los Ángeles, el abandono de la tierra por sus élites, un contexto social multicultural, así como la presencia de tecnologías de vigilancia social. El trabajo muestra cómo estas películas construyen una idea de lo latinoamericano que da sentido a los escenarios apocalípticos futuros, y proyectan a la vez el presente de las sociedades latinoamericanas.

Palabras clave: ficción, iconos, distopías, cine.

Asbtract: This paper highlights how dystopias projected filmic forms of domination and a set of social tensions in contemporary societies. Blade Runner and Elysium movies are analyzed using four iconographic elements that share: Los Angeles city, abandonment of land by its elites, a multicultural social context, and the presence of social surveillance technologies. The paper explore how these films construct an idea of Latin American, who gives meaning to the futuristic apocalyptic scenarios that draw, while projecting the apocalyptic scenario that Latin America lives today.

Keywords: icons, fiction, dystopias, films.

Nelson Arteaga-Botello, doctor en sociología por la Universidad de Alicante, España. Profesor-investigador en FLACSO, México. Temas de especialización: violencia, seguridad y sociología cultural. Correo electrónico: nelson.arteaga@flacso.edu.mx.
Enviado a dictamen: 26 de enero de 2015. Aprobación: 13 de abril de 2015 Revisiones: 1 . 


\section{Introducción}

L as películas distópicas dibujan sociedades futuras que proyectan la desaparición de la libertad, la individualidad y la autonomía, ya sea frente al poder estatal o ante grandes corporaciones privadas. Delinean ambientes donde supercomputadoras y androides vigilan permanentemente a la población. Por lo general, la trama de estos filmes se dirige a mostrar cómo los sujetos resisten y enfrentan estos sistemas de vigilancia. Ejemplos de escenarios distópicos pueden observarse en películas como Metropolis, 1984, Escape from New York, Robocop, 12 Monkeys, Farenheit 451, Brazil, Logan's Run, Matrix, Minority Report o V of Vendetta.

Estos filmes despliegan escenarios en los que se da cuenta de un futuro en el que han colapsado los valores de la sociedad occidental. En ambientes oscuros y sombríos, los protagonistas portan vestimentas que denotan el reciclaje y el desgaste. Las historias se llevan a cabo en ciudades devastadas, donde el exceso de dispositivos tecnológicos anuncia procesos claros de deshumanización. Estas películas se desenvuelven por lo regular en el marco de un cierto multiculturalismo que mezcla razas, etnias y lenguas. Cabe resaltar que a partir de la década de los ochenta lo latinoamericano da cuerpo a los escenarios distópicos - la presencia del idioma español es mayor y aparecen grupos sociales de esta región del globo - ${ }^{1}$ Pareciera que ello proporciona un ambiente en el que no sólo discurre la trama, sino que sirve como prueba del grado de descomposición social que podrían vivir las sociedades en el futuro. Por tanto, las películas distópicas expresan el miedo de las sociedades occidentales a perder su identidad basada en la hegemonía de la cultura anglosajona. Como Erreguerena (2011) señala, reflejan una especie de manifiesto de resistencia al futuro.

Losfilmes de este tipo son una articulación imaginada e idealizada de las relaciones sociales y muestran cómo se articulan y distinguen los espacios de dominación y poder (Nellis, 2009). Sin embargo, expresan más que una catarsis sobre los posibles riesgos y temores que enfrentan las sociedades modernas, porque construyen un conjunto de representaciones acerca de actores y eventos sociales en proceso. De esta forma, crean marcos interpretativos en los que se distinguen dinámicas y procesos sociales que resultan relevantes para la modelación actual de las relaciones políticas y culturales. Los filmes - siguiendo el planteamiento de Alexander (2006) - despliegan un repertorio de categorías dicotómicas que revelan dinámicas sociales y personajes en situaciones típicas que cuestionan o idealizan una serie de valores, tales como el poder, la dominación, la libertad, la individualidad y las formas de convivencia social. En el presente trabajo se subraya cómo ciertas distopías fílmicas proyectan formas específicas de dominación y un conjunto de tensiones en las sociedades contemporáneas.

Se considera que los filmes Blade Runner (1982) y Elysium (2013) articulan de forma particular estos y otros elementos propios de las distopías cinematográficas. Primero, esbozan un futuro en el que las élites abandonan la tierra, heredándola a los pobres, criminales y enfermos. En segundo lugar, comparten como escenario la ciudad de Los Ángeles, ya sea como una urbanización altamente tecnificada, oscura y húmeda en Blade Runner, o como una gran zona marginal muy semejante a las villas miseria, favelas y ciudades perdidas de América Latina, como se muestra en Elysium. En tercer lugar, las dos historias se desenvuelven en sociedades en las que predomina la población latinoamericana en términos demográficos y culturales. Finalmente, ambas películas presentan dispositivos tecnológicos de vigilancia biométrica, al igual que de vigilancia vertical del espacio urbano. Estos dos filmes construyen cuatro figuraciones que pueden ser consideradas — siguiendo los planteamientos de la sociología cultural- como objetos que tienen una fuerza simbólica y estética; en otras palabras, constituyen una cierta conciencia iconográfica sobre el futuro de la humanidad. ${ }^{2}$

Con el fin de apoyar el análisis que se propone aquí, el artículo abre con una breve revisión de conceptos básicos y una propuesta metodológica de análisis. Posteriormente se describe la trama argumentativa de Blade Runner y Elysium, para dar cuenta del peso de los cuatro íconos del desastre que comparten. A continuación, en el documento se examina cómo dichos 
íconos magnifican procesos sociales actuales, dando cuenta del desastre que viene a futuro. Finalmente el artículo concluye con una serie de reflexiones en las que se subraya cómo determinadas visiones del futuro expresan un tipo particular de guerra de las imágenes, a través de la cual la occidentalización del mundo deposita e impone, como sugiere Gruzinski (1994), sus imaginarios sobre América Latina.

\section{Conciencia icónica ${ }^{3}$}

Siguiendo a Alexander (2006), las narrativas fílmicas pueden entenderse como formas simbólicas que tejen códigos binarios que reflejan los posibles modelos de libertad y autonomía social frente a las relaciones autoritarias. Las novelas y los filmes no son, como sugiere Habermas (1989), "sustitutos de relaciones con la realidad", que permiten a los lectores entrar en la acción de ficción como "un fondo de entrenamiento para la reflexión pública crítica" o como un "precursor literario de la esfera pública", sino proyecciones e identificaciones estéticas, como dimensiones vitales en la formación de la opinión pública y del discurso civil. En otras palabras, las narrativas de ficción no son laboratorios ni espacios en los que se entrena la capacidad crítica, más bien conciben modelos de libertad y autonomía. Estos modelos expresan de forma problemática vivencias específicas. Las narrativas de ficción problematizan y estandarizan el marco de compresión de ciertos problemas al conjunto social, a la vez que proyectan sentimientos diversos, situaciones, tensiones y conflictos que muy difícilmente pueden materializarse si no es a través de la ficción. ${ }^{4}$ De esta forma, permiten entender nuestras sociedades actuales por juegos de comparación, entre objetos sagrados y profanos que se mueven en distintos tiempos: el pasado, el presente, las utopías y distopías (Marks, 2005; Karmmerer, 2012). Al problematizar temas como la libertad, la autonomía y la individualidad, se apela a la reflexión sobre los valores en situaciones prácticas y concretas (Nussbaum, 1990). De igual forma, se puede ver a seres humanos en momentos en los que se cuestionan principios morales y el propio sentido de lo humano
(Rorty, 1989). Finalmente, proyectan situaciones en las que los personajes se involucran en dilemas éticos con efectos políticos y sociales (Whitebrook, 1996).

Las narrativas fílmicas que se analizan en este trabajo dibujan un repertorio de categorías dicotómicas que revela dinámicas sociales y personajes en situaciones típicas que cuestionan o idealizan una serie de valores tales como el poder, la dominación, la libertad y la individualidad. Refieren a constelaciones de significantes que adquieren una materialidad visual en el mundo social a través de objetos que expresan ideas sobre la libertad u opresión, la debilidad o la fortaleza. Los íconos pueden ser vistos como condensaciones simbólicas de sentido social que están cristalizadas de forma material o visual, lo que permite que las abstracciones morales que se encuentran tras ellos se hagan visibles por vía de elementos estéticos y, así, plasman formas específicas de cognición y clasificación del mundo social. El sentido icónico se hace visible, sugiere Alexander (2010), a través de algo hermoso, sublime, feo, incluso en la vida material banal. La conciencia icónica aparece cuando una forma estética material adquiere un valor social. No obstante, el contacto con la superficie estética no es comunicacional en un sentido convencional, sino que está más relacionado con la remembranza de experiencias y emociones. Para ser icónicamente conscientes es necesario entender sin conocer; en otras palabras, entender por vía de las emociones o por la "evidencia del sentido", más que por el discernimiento que se podría denominar puramente racional.

Los íconos son el resultado de la transformación en materia de un significante - una idea-, que deja de estar sólo en la mente para metamorfosearse en algo experimentado, que se siente en el corazón y en el cuerpo (Alexander, 2010). Esto significa que la conciencia icónica se encuentra inmersa en procesos semióticos que definen códigos binarios (Bartma'nski, 2011). Adquieren un "aura" especial que los puede transformar en objetos mágicos (Alexander, 2010). Al igual que los símbolos, los íconos asumen características que los ubican como sagrados o profanos. Siguiendo a Durkheim (2003), dado que la moralidad es abstracta y 
se puede imaginar con dificultad, podemos comprender los sentimientos espirituales sólo en conexión con objetos concretos. Los íconos proporcionan esta materialidad.

La ciudad de Los Ángeles, las tecnologías de la vigilancia, la autosegregación de las élites y el ambiente multicultural con acento en una cierta idea de lo latinoamericano, se proyectan como los cuatro íconos de las sociedades contemporáneas que adquieren una textualidad en Blade Runner y Elysium: constituyen los elementos que definen el perfil de lo apocalíptico. Conectando estos íconos entre su presente y su posible futuro - como puentes entre el hoy y el mañana-, los filmes proyectan los miedos y esperanzas sobre el futuro de una de las ciudades más importantes del norte global. La ciudad de Los Ángeles, como nodo de la industria fílmica mundial, se presenta como una ciudad destruida, como si las revueltas de 1992 por el caso Rodney King se hubieran eternizado, o el barrio de Skid Row se hubiera expandido al conjunto de la ciudad. En ambas películas las élites económicas y políticas se han aislado del mundo, enfatizando con ello, como sugiere Davis (2001), los procesos de autosegregación de las élites en ciudades verticales y vecindarios cerrados. Por otra parte, las tecnologías de vigilancia implementadas en Los Ángeles, que construyen una especie de panóptico urbano (Davis, 2000), son expuestas en los filmes como mecanismos de control social exhaustivos y omnipresentes. Finalmente, la multiculturalidad y multirracialidad que forman parte de la historia de esa ciudad, marcada por la presencia de distintos grupos de herencia hispana e indígena, se dilatan de tal manera que terminan por desbordarla. En este sentido, ambas películas proyectan los miedos y esperanzas que hoy en día parecen constituir el imaginario de una parte importante de la sociedad norteamericana a nombre, pareciera ser, del resto de los países desarrollados.

El conjunto de imágenes que despliegan ambas películas está organizado de tal manera que, a través de técnicas y procedimientos cinematográficos, logran hacer evidentes para el espectador los elementos clave que construyen la secuencia y desarrollo de sus historias. Como señala Morales y Mas (2009) desde la teoría narrativa y cinematográfica, el equilibrio de estas técnicas permite al espectador seguir e hilvanar de manera coherente y atenta el desarrollo de la trama hasta su desenlace final. Esto incluye, por supuesto, la música, que da un tono y acento particular al desarrollo de la trama. Si losíconos que aquí se analizan impactan en el nivel de las emociones es porque, como apuntan Conde y de Iturrate (2002), la diversidad de actores según sexo, edad, nivel socioeconómico y etnia permite a los espectadores identificarse con la trama. Ciertamente, las emociones se encuentran mediadas socialmente, pero también dependen de las características cognitivas, racionales y emotivas del espectador, así como de las experiencias que éste haya acumulado en el transcurso de su vida (Cepeda, 2005).

No obstante, la circulación de ciertas películas a escala mundial parece sugerir la presencia de un proceso de globalización de la emociones (León, 2012), en parte porque se ha instaurado una serie de íconos que se imponen como referentes de lo simbólico en el conjunto del orbe. Esto permite que se pueda establecer siempre una relación de proximidad, pero también de distancia, entre los espectadores de la misma película en función de su entorno nacional y regional. Aunque el objetivo de este trabajo no es hacer una exploración de la recepción de Blade Runner y Elysium entre los espectadores, era conveniente señalar la relación que podrían tener los filmes con los espectadores, esos grandes olvidados de los análisis cinematográficos. Como ya se mencionó, la intención es resaltar desde las bases de la sociología cultural cómo el cine, en tanto medio de comunicación de masas que define identidades nacionales y globales, construye representaciones míticas e íconos sobre motivos, relaciones e instituciones sociales (Alexander, 2006), sobre todo a partir del dominio que establece la industria de Hollywood.

Cabehacer aquíuna necesariaacotaciónmetodológica. Si bien en este artículo la propuesta no es hacer un análisis cinematográfico en estricto sentido, sino en el contexto de la sociología cultural, se retoman aspectos de la técnica cinematográfica y la narrativa que resultan pertinentes para los objetivos que se busca alcanzar. Siguiendo la propuesta de Zavala (2014), el análisis de cada película 
arranca con el reconocimiento de la organización de la película — unidad estructural—-, se establecen las secuencias de su narrativa y se destacan algunas escenas y planos que dan sustento para considerar los elementos que comparten Blade Runner y Elysium. De esta forma, se hace un microanálisis de estos elementos como construcciones mitológicas (Volgler, 1998) de lo apocalíptico.

Posteriormente se organiza el análisis a partir de establecer las condiciones de interpretación de las películas, subrayando el contexto simbólico de la lectura y señalando algunos de sus antecedentes. Se pone énfasis en el peso de algunas imágenes a partir de su color, iluminación, composición y algunos movimientos de cámara. Se hace hincapié también en los escenarios - los espacios, la arquitectura o la dimensión simbólica de los objetos-, así como en el contexto urbano y en el tipo de personajes y grupos sociales que enmarcan las películas. Como parte central del trabajo, se hace un esfuerzo por resaltar la intertextualidad entre ambos filmes: el tipo de estrategias visuales que comparten, y cómo en Elysium se citan y mencionan-con una distancia de 31 años- elementos clave de Blade Runner. Además, se subraya la forma en que comparten o no un mismo contexto ideológico, marcado por la presencia de un régimen de vigilancia y de exclusión social inserto, paradójicamente, en cierto multiculturalismo.

\section{Años 2019 y 2154 en la tierra}

La película Blade Runner transcurre en la ciudad de Los Ángeles, en Estados Unidos, en el año 2019. ${ }^{5}$ Las formas de vida en la tierra han sido casi exterminadas por el uso de armas biológicas y radioactivas. El planeta ha quedado contaminado y gran parte de la población sobreviviente presenta mutaciones. La mayoría de los humanos aún sanos ha migrado a otros planetas, dejando al resto a su suerte en la tierra y con la prohibición de salir de ella. El gobierno despliega una vigilancia cuidadosa que se orienta a evitar, por un lado, la migración de la población mutante o enferma y, por otro, el ingreso a la tierra de "replicantes", androides orgánicos indistinguibles de los humanos, que son utilizados como esclavos o soldados y que han sido proscritos de la tierra por amotinarse constantemente.

La trama de la película se centra en la persecución de varios replicantes que han logrado llegar a la tierra: la serie Nexus-6. Prácticamente perfectos, les han sido implantados recuerdos, lo que les permite generar sentimientos y formas específicas de empatía. Su objetivo en la tierra es buscar a los ingenieros que los diseñaron para alargar su vida, la cual se encuentra limitada a cuatro años. La policía solicita los servicios de un exoficial de policía, Rick Deckard, un bladerunner o cazador de replicantes. En su aventura asesina, termina por enamorarse de Rachel, una replicante que piensa que es humana. Una vez que Deckard ha eliminado a los Nexus-6, escapa con Rachel a sabiendas de que otro blade runner - de nombre Gaff- conoce la condición no humana de su amada. "Es una lástima que ella no sobrevivirá... pero iquién sobrevive?" Es la frase que, como amenaza velada, Gaff dirige a Deckard poco antes de que éste huya con Rachel. ${ }^{6}$

El escenario de la película es la ciudad de Los Ángeles sumergida en una oscuridad y lluvia eternas. Los edificios son luminosos rascacielos cuyas raíces son oscuras calles alumbradas por luces de neón, y conforme ganan altura rompen el cielo con enormes pantallas que cuelgan de ellos, para terminar coronados por enormes chimeneas que arrojan vapor y fuego. El edificio más imponente de la ciudad es el de la corporación Tyrell - la productora y diseñadora de los androides orgánicos-, una enorme pirámide de cientos de pisos que se inspira en la arquitectura de Hugh Ferries y Raymond Hood, así como del "[...] arquitectoarqueólogo mexicano Francisco Mújica” (Davis, 2001: 5). De esta suerte, las moles arquitectónicas recuerdan, como sugiere Gruzinski (1994), a los grandes templos precolombinos de Teotihuacán.

En términos sociales, el ambiente de la ciudad se caracteriza por cierta polifonía lingüística, marcada por el inglés, el español, el japonés, el chino y el camboyano, lo que da cuenta de un cierto poliglotismo devastador (Davis, 2001). La ciudad se encuentra habitada por personas de distintas procedencias étnicas, por lo que se desvanece casi cualquier rasgo de cultura anglosajona, lo 
que motiva una especie de pánico racial en el espectador norteamericano o europeo (Massey, 2000). De hecho, se puede observar que el protagonista de la película se esfuerza por entender lo que otras personas le quieren decir, ya sea porque hablan en idiomas que fusionan distintas lenguas o porque simplemente no hablan adecuadamente el inglés. La búsqueda de replicantes por parte de Deckard está ambientada en todo momento por frases y palabras en español, que se combinan además con palabras en chino y alemán (Williams, 1988). La música de fondo está construida con tonos del Medio Oriente y Oriente. ${ }^{7}$ De esta forma, la combinación de razas, lenguas y culturas se fusiona con el mobiliario escenográfico, que simula un basurero tecnológico conformado por desechos urbanos decadentes (Bruno, 1987), lo que confirma que, al parecer, cada uno de estos elementos va entrelazado.

En Elysium se abordan también algunos de estos elementos que aparecen en Blade Runner. ${ }^{8}$ Ambientada en el año 2154, la tierra ha sido abandonada por los más ricos, quienes se han ido a vivir a un satélite que gira a su alrededor. Gracias a su campo gravitacional artificial logra reproducir las condiciones de vida de los suburbios americanos: grandes extensiones de jardines, canchas de golf, escuelas y, sobre todo, la plataforma satelital, que cuenta con cápsulas médicas que pueden detectar y curar cualquier enfermedad. El resto de la población, la mayoría, vive en la tierra en condiciones de pobreza extrema, racionamiento de comida y bajo un sistema de salud incapaz de garantizar la atención médica de la población..$^{9}$ Por si fuera poco, existe un férreo control social por parte de androides y sistemas de vigilancia biométricos, con cámaras de vigilancia, drones y pulseras que miden las reacciones bioquímicas del cuerpo para "predecir" comportamientos violentos o delictivos. Dicha sociedad policial se encuentra bajo las órdenes de un gobierno establecido en la estación satelital que, además de monopolizar el poder político y los beneficios del sistema de salud, define los criterios de ejercicio de la ciudadanía.

La trama de la película se centra en Max da Costa, un expresidiario que trabaja en una planta en la que se fabrican los robots policías que pertenecen a la empresa
Armadyne, la cual construyó Elysium, así como el sistema computacional que mantiene funcionando el conjunto de la sociedad. El protagonista, como la mayoría de los empleados de la fábrica, se encuentra presionado por mantener su trabajo. Cualquier error o falla causa un despido inmediato, por lo que se esfuerza en mantener el funcionamiento de la máquina a su cargo, incluso a costa de su vida. De hecho, por tal razón queda expuesto a radiación letal. Dado que el daño que recibe sólo puede ser reparado en las cápsulas médicas que hay en Elysium, acepta secuestrar al presidente de Armadyne, John Carlyle, para sustraerle información orgánica alojada en su cerebro: bases de datos, cuentas bancarias, claves de acceso y cualquier otra información acerca de Elysium.

Da Costa logra extraer la información de Carlyle no sin complicaciones. El gobierno lo chantajea a través de un mercenario para que devuelva la información a cambio de no asesinar a la única persona que ama. Durante la trama, Da Costa descubre que Carlyle y la secretaria de Defensa de la plataforma satelital han planeado con antelación un golpe de Estado a fin de recrudecer los mecanismos de vigilancia e impedir por la vía armada que los migrantes lleguen a Elysium. Da Costa no logra curarse y muere, pero en el proceso alcanza a reiniciar el sistema que sostiene el orden social. Su acto heroico transforma a los habitantes de la tierra en ciudadanos de Elysium, asegurando que las cápsulas médicas lleguen a la tierra en forma masiva para asistir a los enfermos.

La ciudad de Los Ángeles en Elysium es también un basurero, pero totalmente diferente. Es un enorme desierto con casas derruidas, calles sin pavimentar y polvorientos terrenos baldíos. La ciudad está bañada por un sol desértico. Los edificios son de dos tipos: por un lado, las pequeñas casas y edificios de cuatro o cinco pisos deteriorados y ubicados en la periferia de Los Ángeles; por el otro, el centro de la ciudad, con sus ruinosos rascacielos coronados con enormes chimeneas que arrojan humo negro. En una de las escenas se puede observar una réplica de la pirámide Tyrell de la película Blade Runner. No obstante, aparece como un edificio que acompaña el deteriorado complejo urbano. En 
términos sociales se puede observar la prevalencia de un marcado bilingüismo en los habitantes de la tierra, particularmente mediante el uso del español y el inglés, aunque también se escucha el afrikáner.

Cabe resaltar al respecto que Da Costa, a diferencia de Deckard, habla inglés y un limitadoespañol — además, un importante número de personajes en la película se expresan en este último idioma-. Quizá son los policías robots que supervisan la vida social los que exclusivamente hablan en inglés. Mientras tanto, en la plataforma satelital se pueden escuchar diálogos en inglés, francés y alemán. Una diferencia entre la plataforma y los habitantes de la tierra radica en el hecho de que, precisamente, predominan los hombres y mujeres caucásicos en uno, y los latinos, aunque también chinos, árabes y negros, en el otro. Se enmarca así una sociedad que se encuentra polarizada: blanca y rica en el espacio; multicultural, multirracial y pobre en la tierra. Por tanto, entre diferencias y similitudes, Blade Runnery Elysium construyen distopías en las que la ciudad de Los Ángeles se presenta como lugar en ruinas y multicultural, gobernado y vigilado desde lo alto.

\section{Íconos del desastre}

Los elementos que se han destacado aquí de las dos películas constituyen íconos que cristalizan formas de clasificar el mundo social a través del desastre de una ciudad como Los Ángeles. Éstos condensan esperanzas y temores que atormentan el imaginario de quienes habitan las ciudades del norte global, pero que se presentan en escenarios futuristas. En primer lugar, el ícono que representa la ciudad de Los Ángeles, en sus versiones oscura-húmeda y soleada-desértica, se proyecta como un espacio inhóspito lejos de las condiciones del clima subtropical-mediterráneo que le caracteriza hoy en día: es en ambos casos una urbe fantasmagórica (Duarte, Firmino y Crestani, 2014). Un marco adecuado para justificar su abandono por quienes tienen la capacidad de hacerlo. Los rascacielos coronados por chimeneas que asemejan una enorme fábrica subrayan la mecanización de la ciudad y, en cierta medida, su deshumanización. Ambas películas comienzan mostrando amplios planos aéreos que dan cuenta del enorme tamaño de la ciudad y su aplastante presencia, lo que sugiere de alguna manera la cantidad de personas que la pueblan. Sus calles, plazas y mercados son los espacios donde se mezclan todas las razas posibles y en ellos se hablan distintos idiomas. Pero la ciudad tiene otra particularidad, es también una gran prisión-hospital, una reserva en la que deambulan enfermos y criminales.

En el otro extremo de la tierra, en el silencio del espacio, se encuentran quienes han podido construir otro mundo. En Blade Runner sólo se puede saber que los migrantes han comenzado de nuevo una vida más allá de la tierra. No aparecen nunca, pero en los diálogos e imágenes se presentan como aquellos humanos afortunados que han podido escapar a la miseria del mundo. En Elysium, estos bienaventurados son claramente perceptibles porque viven en enormes áreas verdes, con cielos azules que contrastan con la oscuridad del espacio y la tierra, presididos por una luna contaminada. Los campos de golf, escuelas y casas remiten claramente a las formas de vida de las clases medias y altas de los países desarrollados, una tranquilidad que es resguardada por un sistema de vigilancia que se encarga de mantener el orden.

Esta distancia entre las ciudades de la miseria y el bienestar, tanto en Elysium como en Blade Runner, se acompaña de mecanismos de control social para evitar que los condenados de la tierra escapen. Se usan para ello distintas tecnologías de vigilancia. La mayoría, de carácter biométrico, transforma los cuerpos humanos en un conjunto de códigos que dan cuenta de la identidad de las personas, su estatus y destino social. No obstante, hay diferencias entre una y otra película. En el caso de Blade Runner, el objetivo es evitar que la población considerada como "indeseable" deje la tierra y que los replicantes lleguen a ella, ${ }^{10}$ mientras que en Elysium el gobierno busca regular la vida de quienes habitan el planeta, ya sea a través de retenes, o detectando estados de ánimo, pronosticando comportamientos violentos y decodificando códigos genéticos. En ambas películas es posible observar también la presencia de dispositivos de vigilancia 
desde el aire. En Blade Runner las patrullas se desplazan por el cielo para monitorear a la población, mientras que en Elysium aparecen no sólo naves que surcan los cielos para perseguir criminales, sino también pequeños drones que, como sabuesos, buscan objetivos humanos determinados. La vigilancia omnipresente se convierte en una forma no sólo de control, sino de intervención para moldear y dirigir la conducta de las personas.

La población sobre la que se ciernen los mecanismos de vigilancia es un mosaico multicultural y multiétnico donde se observa el papel específico de lo que se considera latinoamericano. No obstante, uno y otro filme guardan diferencias. Por un lado, lo latinoamericano se pierde en las distintas escenas de la película Blade Runner, como voces que ambientan el desarrollo de la trama, sobre todo en exteriores. Por otro lado, adquiere un peso fundamental en la figura de Gaff, el policíapachuco que lo acompaña y vigila, el cual funciona como la conciencia que interpela constantemente al personaje principal. Este es quien lleva a Deckard a la estación de policía para que regrese a sus labores de cazador de replicantes. Gaff es quien mantiene una vigilancia estrecha sobre los movimientos de Deckard en su azaroso recorrido por Los Ángeles. Es él quien finalmente sabe de la condición de replicante de Rachel, y quien amenaza con retirarla y, con ella, al propio Deckard, de quien se llega a sugerir que también es un robot orgánico. Por el contrario, lo latinoamericano en Elysium está constantemente presente, tanto como telón de fondo, como en los protagonistas que acompañan la travesía de Da Costa. Sin embargo, van muriendo, y por tanto desapareciendo de escena, conforme trascurre la película: los latinoamericanos pierden fuerza escénica como protagonistas de la película y se transforman al transcurrir los minutos en entes pasivos frente a la valentía y determinación, pero sobre todo la capacidad de supervivencia de Da Costa. Sin embargo, pese a este desvanecimiento, hay que reconocer que el director de la película, Neill Blomkamp, pudo "[...] mediante jirones culturales, posiciones dislocadas, miradas periféricas y fragmentarias [imaginar la globalización en América Latina] desde las experiencias violentas y traumáticas del imperialismo, el colonialismo y la esclavitud" (Pizarro y Benavente, 2014: 394).

Lo latinoamericano parece ser parte esencial del marco distópico de las películas que aquí se analizan: un ingrediente sustancial que da cuerpo a la construcción de escenarios apocalípticos, como si el fin de la sociedad que hoy conocemos tuviera algo que ver con la presencia de lo latinoamericano, una presencia que anuncia la descomposición de las formas de organización democrática, del respeto a la individualidad o de la sustentabilidad del desarrollo urbano y que refleja la eclosión de la sociedad occidental. No obstante, no se hace de la misma manera en ambos filmes. En el caso de Blade Runner, Gaff es un ícono del mestizaje que hace ver permanentemente a Decker la imposibilidad de trascender la fatalidad que se cierne sobre él: es la presencia de lo latinoamericano la que le recuerda que vive en un mundo que ya no puede controlar, y al que no queda más que resignarse. Sin embargo, en Elysium la población latinoamericana es un virus que puede ser neutralizado, occidentalizado y humanizado a través de su medicalización gracias al sacrificio del protagonista.

\section{El futuro es el presente}

Las películas que se analizan en este artículo movilizan así una serie de íconos que proyectan en clave de futuro nuestro presente. Muestran el miedo a la contaminación social por grupos sociales no anglosajones: la favelización de las ciudades del norte global. Visibilizan los mecanismos de vigilancia que se necesitan para contener a los enormes grupos de población latinoamericana. Describen el aislamiento de las élites sociales para no contaminarse de la diversidad de razas, culturas y lenguas. Pero, sobre todo, enseñan que el proceso de mezcla e hibridación étnica causa el inevitable y lastimero futuro de la sociedad contemporánea.

Los íconos del apocalipsis resultan entonces constelaciones de significantes que adquieren una materialidad visual, que pueden ser vistos como condensaciones simbólicas de sentido social que se cristalizan de forma específica en estas tramas 
fílmicas. A través de elementos estéticos, hacen visibles abstracciones morales sobre los elementos que caracterizarían la posible sociedad futura en la que han colapsado las virtudes morales de la sociedad. De esta manera, establecen formas de cognición y clasificación del mundo social que permiten ver, a través de una narrativa futurista, los elementos que desde el presente anuncian el advenimiento del desastre. Proyectan el presente apocalíptico que vive América Latina hoy en día.

En Elysium la imaginería del desastre que se vive en la tierra, así como el bienestar que se vive en la plataforma satelital, refieren directamente a espacios del presente. Las zonas marginadas de los municipios de Ecatepec, Nezahualcóyotl, Naucalpan, Valle de Chalco y el basurero del Bordo de Xochiaca, en el estado de México, son los escenarios donde se filma esa ciudad de Los Ángeles del año 2154, ${ }^{11}$ mientras que la plataforma Elysium está filmada en los suburbios de la Columbia Británica, combinados con paisajes de Beverly Hills y Bel Air. ${ }^{12}$ La película evidencia los contrastes presentes entre las condiciones de vida urbana de las ciudades del norte y el sur global, pero verticalizadas para acentuar y evidenciar su disparidad.

Por otro lado, las formas de vigilancia que permiten la gestión de la población, tanto en esta película como en Blade Runner, expresan al extremo el uso de tecnologías que se usan ya en ciertos países de América Latina para controlar la migración, la delincuencia y los grupos depauperados considerados como potencialmente peligrosos —de hecho, como apunta Fernández (2001), esa película constata los procesos de exclusión y control social en América Latina y África-. Weizman (2002) denomina "política de la verticalidad" a este proceso en el que la gestión gubernamental utiliza la mirada desde lo alto como criterio de observación e intervención sobre espacios y grupos sociales con el fin de garantizar la seguridad. ${ }^{13}$ La altura no tiene un mero fin estratégico: proyecta una determinada morfología del Estado. Históricamente el castillo, la montaña y las plataformas han sido los lugares para asentar los poderes estatales, por lo que se transforman así en íconos de poder. La verticalidad estatal genera la sensación de control y vigilancia de un poder cuasi omnipresente. La actual operación de satélites, drones y cámaras de vigilancia que observan desde lugares apartados, optiman la mirada vertical potenciando la observación gubernamental, proyectando y condensando esa propiedad de fuerza y omnipresencia frente a la población.

De esta forma, tanto Blade Runner como Elysium proyectan claramente la sensación de que los grupos dominantes y sus instituciones se encuentran en lo alto; literalmente están por arriba de los grupos dominados, en una especie de proyección hobbseana tridimensional de la posible política del futuro ya contenida en nuestro presente. ${ }^{14}$ En dicha proyección se cristalizan tanto una cultura y una política, como un uso de la tecnología. Son expresiones que subrayan la conexión entre formas de conocimiento biológico y de poder, y una empresa cultural en la que la diversidad social y racial se expone como potencialmente peligrosa. Proyectan hacia el futuro una forma de dominación del territorio y de la población que está incubada ya en el presente, una de cuyas expresiones más claras son las políticas de seguridad pública que están generando procesos de segregación urbana y social, al tiempo que refuerzan las lógicas de clasificación de grupos sociales como targets. Un proceso que se encuentra impulsado por la urbanización de las ciudades, si se considera que tres de cada cinco planificadores urbanos afirman que esperan que Los Ángeles sea en el futuro como en Blade Runner (Klein, 1991). Un modelo que se piensa, además, que debe caracterizar a las ciudades a escala global (Davis, 2000). El caso de la ciudad de Buenos Aires, como sugiere Laborde (2011), parece transmutar a Sudamérica la multiculturalidad que mezcla población china, boliviana y armenia, en una estética urbana muy cercana a la que imagina Ridley Scott.

Ambas películas galvanizan la idea de que la inseguridad y las expresiones de inestabilidad social son problemas que derivan de la polución que representa la presencia de lo latinoamericano en la sociedad norteamericana - esta última como representación de la sociedad global-. De esta forma, los estereotipos que dominan en un sector de la sociedad norteamericana se proyectan como globales, transformando una visión parroquial del apocalipsis en una visión global de 
la cultura popular occidental (Ewen y Ewen, 2008). Los latinoamericanos se proyectan en ambos casos desbordando las fronteras de la civilización, pero viviendo en condiciones cuasi salvajes, marcados por la violencia y contaminados en sus cuerpos y en su sangre: expresiones de la degeneración moral y biológica de lo que en otros tiempos se llamó Occidente.

Sin embargo, el peso que se da a este último elemento resulta diferente en una y otra película. En Blade Runner, lo latinoamericano queda reducido al sonido ambiental de una multitud anónima y a las evocaciones teotihuacanas en la pirámide Tyrell, mientras que en Elysium la presencia de los referentes de la cultura latinoamericana desbordan casi todas las escenas. Sin embargo, en ambos casos esta presencia apela a la descomposición de las sociedades occidentales, lo que refleja aquello que Gruzinski (1994) encuentra como pieza clave en Blade Runner: las culturas mezcladas y contaminadas como depósito de residuos de la modernidad y la posmodernidad.

\section{Conclusiones}

Las distopías permiten dramatizar las tensiones, esperanzas y temores que viven las sociedades contemporáneas (Abbott, 2007; Kitchin y Kneale, 2001). Proveen, además, espacios cognitivos que permiten visualizar las morfologías de la dominación y el poder (Campbell, 2010). Propician escenarios de resistencia al futuro, pero también proyectos que buscan transformar la ficción en realidad (Dodge y Kitchin, 2000). Estos puntos pueden contribuir, como se ha intentado hacer en el presente artículo, a enmarcar más ampliamente el análisis de las distopías desde la academia. Por otro lado, abren una veta de trabajo para explorar el tema de los temores sociales del presente, en clave del futuro, en las series de televisión, juegos de computadora, videos musicales o anuncios comerciales (Lauer, 2011).

Estas ficciones proyectan modelos de sociedad en los que se pone en tensión la sensación de incertidumbre que sugiere la presencia de ciertas dinámicas sociales, como las que se han descrito aquí: el multiculturalismo, lo latinoamericano y las tecnologías de vigilancia. Los discursos en la esfera pública y civil que subrayan el temor sobre lo que "podría suceder si..." cada uno de los íconos aquí analizados se materializara, desatan no sólo la imaginería especulativa sobre posibles amenazas, sino que refuerzan el ímpetu en las entidades gubernamentales y privadas por llevar a la realidad dispositivos del mundo de la ficción. Por tanto, parafraseando a Cohen (1985), esta iconografía de la distopía está enraizada profundamente en nuestras fantasías, visiones y expectativas sobre los efectos constitutivos, y a veces perversos, de la modernidad.

Al retratar estas situaciones de angustia sobre el sentido del futuro, los filmes, unos de una forma más crítica que otra, nos identifican y corporizan en esa angustia, ya sea porque la padecemos en nuestra experiencia cotidiana o porque a veces contribuimos a su desarrollo. Los filmes, en este sentido, ayudan a entender estos procesos en más de un sentido y en diferente intensidad. Esto depende también de las mediaciones sociales que se establecen entre la ficción y su audiencia, lo que ciertamente es un punto central. Las ficciones proyectan las tensiones y los conflictos entre individuos y grupos, pero esto no significa que de inmediato se establezca una conexión entre lo que sucede en la ficción y los problemas concretos que se enfrentan en el día a día. Quizás en este sentido convendría explorar en otras investigaciones cómo este tipo de construcciones estéticas modelan y son modeladas por quienes las consumen, y en qué medida esto impacta en la construcción de una sociedad más crítica o complaciente con los regímenes contemporáneos de dominación.

Esto último no es un tema menor. Las películas a las que se ha pasado revista aquí expresan las formas en cómo se piensa que terminará la occidentalización del planeta: contaminada por ese otro que intentó comprender y dominar. A diferencia de las distopías fílmicas tradicionales como 1984, Farenheit 451 o Brazil, en las que el temor está centrado en la presencia de un "gran hermano", un "ministerio de la verdad" o un enorme Leviatán, Blade Runner y Elysium ubican el sentido de crisis en una sociedad contaminada y atestada de culturas que se mezclan, que llevan al extremo la 
diferenciación social y que colapsan la vida urbana, lo cual justifica, a todas luces, la operación masiva de distintos dispositivos de vigilancia. Todos estos son íconos que no sólo reflejan una forma de percibir los problemas del futuro en el presente, sino que también son dispositivos desde los cuales se impone un imaginario sobre América Latina. Siguiendo a Gruzinski (1994), la imagen constituye una de las principales herramientas de la cultura occidental europea, y su expansión al resto del mundo ha tenido como pieza clave el despliegue de una guerra de imágenes que parece no haber concluido. En este sentido, habría que preguntarse en qué momento los filmes analizados aquí, entre otros, forman parte de esa guerra de imágenes en la que una cierta iconografía del desastre pone a sus protagonistas latinoamericanos como piezas centrales de la calamidad que está aparentemente por venir, pero que está encriptada en las sociedades del norte y sur global contemporáneas. Pero sobre todo obliga a pensar cómo desde esta última región del planeta se repiten, reproducen, transforman y mediatizan dichas imágenes e íconos por quienes son señalados como los principales responsables de contaminar la sociedad del futuro.

\section{Notas}

${ }^{1}$ Algunos ejemplos pueden encontrarse en Matrix Reloaded (2003), Terminator (1984), Escape from LA (1996), The Running Man (1987) y Strange Days (1995).

${ }^{2}$ Se reconoce que estos elementos dan cuerpo a lo que se conoce en el análisis cinematográfico como la lexía, elementos específicos que comparten, en este caso, ambas películas.

${ }^{3}$ Las reflexiones presentadas en este apartado pueden encontrarse desarrolladas de forma amplia en Arteaga (2014), así como en Arteaga y Arzuaga (2015), en el marco del análisis de novelas distópicas y conciencias icónicas en los actuales movimientos sociales.

${ }^{4}$ Para profundizar en esta perspectiva de análisis de las ficciones literarias, ver Williams (2001), Jameson (1989), Pia (1998) y Brooks (2005).

5 Blade Runner (1982) fue dirigida por Ridley Scott y distribuida por Warner Bros. El filme se inspiró en la novela ¿Sueñan los androides con ovejas eléctricas?, escrita y publicada por Philip K. Dick en 1968. Existe una importante literatura alrededor de Blade Runner: como paisaje de miedo que se proyecta en la ciudad de Los Ángeles (Gold y Deviil, 2003), como espacio cognitivo de paisajes urbanos futuristas (Kitchin y Kneale, 2001), como representación de la guerra (Williams, 1991), como condensación de las ideologías conservadoras y liberales (Feixa, Periera y Juris, 2009) o como espacio para pensar la teoría política (Williams, 1988). Desde Hispanoamérica, es interesante el texto publicado por Tusquets en 1988 (Argullol et al.), que reúne trabajos de once escritores, la mayoría de ellos españoles. Los temas que abordan sobre la película desafortunadamente no están conectados con temas o problemáticas ni de España ni de América Latina. En general, se podría decir que la película ha sido interpretada como una alegoría de la condición humana y la deshumanización. Aquí estos temas se dejan de lado porque interesa observar cómo se construye a través de ella un cierto número de íconos que establecen el escenario del desastre futurista de la sociedad occidental.

6 Existen dos finales autorizados de Blade Runner. La versión que apareció por primera vez en cine concluye con el escape de Deckard y Rachel hacia un campo dibujado por idílicos prados verdes y un cielo azul, mientras que, en la versión del director, ambos protagonistas terminan huyendo, al parecer, de Gaff, quien va tras ellos.

${ }^{7}$ La música de la película fue compuesta por Vangelis, quien ha creado música original para otras películas como Carros de Fuego (1981) y 1492 (1992).

8 Elysium (2013) fue dirigida por Neill Bloomkamp y distribuida por TriStar Pictures.

${ }^{9}$ En este contexto, los habitantes de la tierra buscan desesperadamente llegar a las bahías de salud de forma ilegal - no hay otra forma de hacerlo- a través de naves espaciales y el robo de los códigos biométricos de los habitantes de Elysium.

${ }^{10}$ El test de Voigt-Kampff para detectar replicantes es, a final de cuentas, un sistema de biovigilancia en el que se correlacionan distintas reacciones faciales y del iris frente a preguntas específicas. 
11 Disponible en: http://www.periodicoafondo.com/main/ index.php?option=com_content\&eview=article\& $\&$ id=3409:lapelicula-eysilum-fue-grabada-en-locaciones-de-nezay-ecatepec\&catid=1:neza;http://mx.covertimes.com/ news/excelsior-mx_2013-04-21/elysium-pobrezafuturista/82499; http:/www.jornada.unam.mx/2014/02/13/ espectaculos/a08nlesp; http://www.apolorama. com/2013/10/tomas-aereas-del-supuesto-los-angeles-deelysium/.

${ }^{12}$ Resulta significativo que el documental La ingeniería de una utopía: creando una sociedad en el cielo, que acompaña la versión en DVD de la película Elysium, muestre las entrevistas al director, diseñador y productor de la plataforma en los municipios donde se filmó la película, subrayando con ello el contraste entre la utopía y la "distopía del presente" en la que viven los pobladores del estado de México.

${ }^{13}$ Uno de los desarrollos tecnológicos más visible de las políticas de verticalidad en América Latina son los vehículos aéreos no tripulados o drones. Diseñados por Estados Unidos e Israel para el control y dominio de la población palestina, han encontrado en nuestra región una tierra fértil para su desarrollo. Argentina, Bolivia, Ecuador, Colombia, México, Brasil, Chile, Venezuela, Uruguay y Perú han puesto en operación estos dispositivos con propósitos similares: monitorear migración ilegal, combatir el tráfico de drogas y el crimen organizado, vigilar límites fronterizos y zonas urbanas consideradas como peligrosas o inseguras, y supervisar protestas sociales (Arteaga, en dictamen). Su presencia tiene efectos en la forma como el Estado define su relación de poder con respecto a sus ciudadanos (Adey, Whitehead y Williams, 2011), y garantizan la construcción de modelos tridimensionales de la realidad que fusionan al mismo tiempo diferentes capas de información — tanto de carácter geográfico, como social y político-económico-.

${ }^{14}$ El texto de Hobbes titulado Leviatán da, por ejemplo, una de las primeras muestra de esta relación entre poder y altitud. Si se pone atención a la figura que aparece en la portada del texto, se puede ver un gigante —conformado por hombres más pequeños- que, por su tamaño, alcanza a cubrir con su mirada el territorio y los habitantes sobre los que gobierna. Además, tiene como primer símbolo de su poder un castillo en lo alto de una cima, desde el cual dirige la fuerza de su ejército. Ambos íconos dan pie a considerar la mirada desde lo alto como un componente esencial para el gobierno de un territorio, sus bienes y la población (Kaplan, 2006), una pieza clave en la conformación del Estado nación moderno que se reproduce posteriormente en los proyectos de dominación colonial (Saint-Amour, 2005). En ambos casos, como sugiere DeNicola (2006), el poder estatal tiende a afincarse en montañas, techos y plataformas desde donde se busca garantizar una mirada privilegiada sobre sus dominios.

\section{Referencias bibliográficas}

Abbott, Carl (2007), "Cyberpunk Cities: Science Fiction Meets Urban Theory”. En Journal of Planning Education and Research, vol. 27, núm. 2, pp. 122-131.

Adey, Peter, Whitehead Mark y Williams Alison J. (2011), "Introduction: Air-target: Distance, Reach and the Politics of Verticality". En Theory Culture Society, vol. 28, núm. 7-8, pp. 173-187.

Alexander, Jeffrey (2010), "Iconic Consciousness: The Material Feeling of Meaning". En Thesis Eleven, vol. 103, núm. 1, pp. 10-25.

Alexander, Jeffrey (2006), The Civil Sphere. Oxford: Oxford University Press.

Argullol, Rafael et al. (1988), Blade Runner. Barcelona: Tusquets.

Arteaga Botello, Nelson (2014), "Metamorfosis de la vigilancia: literatura y sociedad de 1984 a Neuromante". En Culturales, vol. 2, núm. 1, pp. 161-186. Arteaga Botello, Nelson (en dictamen), "Política de la verticalidad: drones, territorio y población en América Latina”. En Región y Sociedad.

Arteaga Botello, Nelson y Javier Arzuaga Magnoni (2015), "El rostro actual de las movilizaciones en la sociedad civil global". En Desacatos [en prensa].

Bartma'nski, Dominik (2011), “Successful icons of failed time: Rethinking post-communist nostalgia”. En Acta Sociologica, vol. 54, núm. 3, pp. 213-231. 
Brooks, Peter (2005), Realist Vision. New Haven: Yale University Press.

Bruno, Giuliana (1987), "Ramble City: Postmodernism and Blade Runner". En A. Kuhn (ed.), Alien Zone: Cultural Theory and Contemporary Science Fiction Cinema. Londres y NuevaYork: Verso.

Campbell, Elaine (2010), "The Future(s) of Risk: Barthes and Baudrillard go to Hollywood". En Crime, Media, Culture, vol. 6, núm. 1, pp. 7-26.

Cepeda, Adriana (2005), "El comportamiento del consumidor del cine: una revisión preliminar de la literatura". En Revista Colombiana de Psicología, núm. 14, pp. 89-99.

Cohen, Stanley (1985), Visions of Social Control. Cambridge: Polity Press.

Conde, Elena y Luis Fernando de Iturrate (2002), "Reacciones emocionales en el cine: el caso de la muerte". En Comunicar, vol. 19, núm. 1, pp. 147-151.

Davis, Mike (2001), Más allá de Blade Runner. Control urbano: la ecología del medio. Barcelona: Virus.

Davis, Mike (2000), City of Quartz: Los Angeles, capitale du future. Paris: La Découverte.

DeNicola, Lane (2006), "The Bundling of Geospatial Information with Everyday Experience”. En Monahan Torin (ed.), Surveillance and Security: Technological Politics and Power in Everyday Life. Nueva York: Routledge.

Dodge, Martin y Bob Kitchin (2000), Mapping Cyberspace. Londres: Routledge

Duarte Fábio, Firmino Rodrigo y Andrei Crestani (2014), "Urban Phantasmagorias: Cinema and the Immanent Future of Cities”. En Space and Culture, vol. 7, núm. 2, pp. 1-11.

Durkheim, Emile (2003), Las formas elementales de la vida religiosa. Madrid: Alianza.

Erreguerena, María Josefa (2001), Resistencia al porvenir. Las distopías en el cine hollywoodense. México: Universidad Autónoma Metropolitana.

Ewen, Stuart y Elizabeth Ewen (2008), Typecasting. On the Arts and Sciences of Human Inequiality. Nueva York: Seven Stories Press.
Feixa, Carles, Ines Pereira y Jeffrey Juris (2009), “Global Citizenship and the 'New, New' Social Movements: Iberian Connections". En Youth, vol. 17, núm. 4, pp. 421-442.

Fernández, Francisco (2001), "Ciudadanos y siervos. El 'hombre mecánico', la justicia y la democracia”. En Realidad: Revista de Ciencias Sociales y Humanidades, núm. 83, pp. 611-623.

Gold, John y Revill, George (2003), "Exploring Landscapes of Fear: Marginality, Spectacle and Surveillance". En Capital \& Class, núm. 80, pp. 27-50.

Gruzinki, Serge (1994), Laguerra de las imágenes. De Cristóbal Colón a 'Blade Runner' (1492-2019). México: Fondo de Cultura Económica.

Habermas, Jürgen (1989), The Structural Transformation of the Public Sphere: An Inquiry into a Category of Bourgeois Society. Cambridge: MIT Press.

Jameson, Fredric (1988), The Ideologies of Theory. Essays 1971-1986. Volume 2: The Syntax of History. Londres: Routledge.

Kammerer, Dietmar (2012), "Surveillance in Literature, Film and Television". En K.D. Haggerty y D. Lyon (eds.), Routledge Handbook of Surveillance Studies. NuevaYork: Routledge.

Kaplan, Caren (2006), "Mobility and War: The Cosmic View of U.S. 'Air Power". En Environment and Planning A, vol. 38, núm. 2, pp. 395-407.

Kitchin, Rob y James Kneale (2001), "Science Fiction or Future Fact? Exploring Imaginative Geographies of the New Millennium". En Progress in Human Geography, vol. 25, núm. 1, pp. 19-35.

Klein, Norman (1991), "Building Blade Runner". En Social Text, núm. 28, pp. 147-152.

Laborde, Soledad (2011), "La alteridad inmigrante en la ciudad del siglo XXI: nuevas formas de construcción del espacio público". En Revista de Ciencias Sociales, núm. 7, pp. 19-44.

Lauer, Josh (2011), "Surveillance history and the history of new media: An evidential paradigm". En New Media Society, vol. 14, núm. 4, pp. 566-582. 
León Geyer, Martín (2012), "Bollywood en Perú. Culturas populares y globalización de las emociones". En Nueva Sociedad, núm. 241, pp. 133-148.

Massey, Doreen (2000), “Angeleno Anomolies”. En New Left Review, núm. 1, pp. 174.

Morales Morante, Luis Fernando y Lluís Mas Machón (2009), "Estructura semántica e impresión emocional del overlapping o encabalgamiento con función expresiva”. Zer, vol. 14, núm. 27, pp. 125-147.

Nellis, Mike (2009), "Since 'Nineteen Eighty Four': Representation of Surveillance in Literary Fiction". En B.J. Goold y D. Neyland (eds.), New Directions in Surveillance and Privacy. Cullompton: Willan Publishing.

Nussbaum, Martha (1990), Love's Knowledge: Essays on Philosophy and Literature. Nueva York: Oxford University Press.

Pia Lara, Maria (1998), "Narrative Cultural Interweavings: Between Fact and Fiction”. En Maria Pia Lara (ed.), Moral Textures: Feminist Narratives in the Public Sphere. Cambridge: Polity Press.

Pizarro, Ana y Carolina Benavente (2014), "Culturas y literaturas de África y América: algunos nexos”. En Letras de Hoje-Estudos e Debates em LinguísticaL literatura e Língua Portuguesa, vol. 49, núm. 4, pp. 391-398.
Rorty, Richard (1989), Contingency, Irony, and Solidarity. Cambridge: Cambridge University Press.

Saint-Amour, Peter (2005), "AirWar Prophecy and Interwar Modernism". En Comparative Literature Studies, vol. 42, núm. 2, pp. 130-161.

Vogler, Christropher (1998), El viaje del escritor. Las estructuras míticas para escritores, guionistas, dramaturgos $y$ novelistas. Barcelona: Ma Non Tropo.

Weizman, Eyal (2002), Hollow Land: Israel's Architecture of Occupation. Londres: Verso.

Whitebrook, Maureen (1996), "Taking the Narrative Turn: What the Novel Has to Offer Political Theory". En J. Horton y A. Baumeister (eds.), Literature and the Political Imagination. Londres: Routledge.

Williams, Douglas (1991), "Concealment and Disclosure: From 'Birth of a Nation' to the Vietnam War Film”. En International Political Science Review, vol. 12, núm. 1, pp. 29-47.

Williams, Douglas (1988), "Ideology as Dystopia: An Interpretation of 'Blade Runner"'. En International Political Science Review, vol. 9, núm. 4, pp. 381-394.

Williams, Raymond (2001), Cultura y sociedad. Buenos Aires: Nueva Visión.

Zavala, Lauro (2014), Narratología y lenguaje audiovisual. Mendoza: Universidad Nacional de Cuyo. 